\title{
PRODUCTION AND MICROSTRUCTURE CHARACTERIZATION OF AA6061 MATRIX ACTIVATED CARBON PARTICULATE REINFORCED COMPOSITE BY FRICTION STIR CASTING METHOD
}

\author{
G. Diju Samuel ${ }^{1}$, J. Edwin Raja Dhas², G. Ramanan³ \\ and M. Ramachandran*,4 \\ ${ }^{1,2}$ Aeronautical Engineering, Noorul Islam Centre for Higher Education, \\ Kanyakumari- 629180, India \\ ${ }^{3}$ Automobile Engineering, Noorul Islam Centre for Higher Education, \\ Kanyakumari- 629180, India \\ ${ }^{4}$ Mechanical Engineering, MPSTME, NMIMS University, Shirpur- 425405, Maharashtra, India. \\ *E-mail: sweetestchandran@gmail.com
}

\begin{abstract}
The purpose of this work is to produce an aluminum metal matrix composite with high strength, low weight with good thermal resistance. For preparing metal matrix composite AA6061 is used as matrix and activated carbon is used as reinforcement and it is cast using modified stir casting technique. The reinforcement activated carbon is added in various weight ratios from $2 \%$ to $8 \%$ of the matrix. The casted metal matrix composites are taken as per ASTM standard by using wire cut process for various tests. Microstructural test like SEM, EDAX, XRD and thermal tests like Fourier Transform infrared spectroscopy and Thermogravimetric tests were taken .From testing results, it is noted that increase in the percentage of activated carbon up to $6 \%$, shows a significant mixing of matrix and reinforcement it is evident in microstructure test result and also shows there is the formation of voids. Thermogravimetric proves the fabricated composite have good thermal resistance by adding activated carbon as reinforcement.
\end{abstract}

Keywords: AA6061, Stir Casting, Activated Carbon, SEM, EDAX, XRD, FTIR.

(C) RASĀYAN. All rights reserved

\section{INTRODUCTION}

MMC (Metal matrix composite) is an unavoidable metal in aerospace and another mechanical engineering field due to the advantage of low weight to strength ratio. Metal matrix composites are one of the most important class of composites for structural, thermal and kinetic applications. Aluminium based hybrid composites have good strength, low weight, good weldability and corrosion resistance. It is mostly used in industries like aerospace engineering, automobile engineering, and marine engineering etc. ${ }^{1,2}$ Stircasting is one of the liquid-state method processes for fabrication of MMC (Metal matrix composite), in which reinforcement(ceramic particles) are mixed with matrix(molten metal) by using the mechanical stirring method. ${ }^{3,4}$ In that observation aluminium fly, ash composite has improved their mechanical properties by adding some suitable percentage of reinforcement. ${ }^{5,6}$ In some other literature, there will be changes in mechanical properties by mixing reinforcements like $\mathrm{SiC}$, $\mathrm{Ti}$, Albite, graphite etc. ${ }^{7,8}$ The tensile and compressive property was improved by adding AA6061 with different weight percentage of albite and graphite. ${ }^{910}$ Activated carbon is one of a type of carbon processed to have low and small volume pores that increase adsorption due to the higher surface area available. ${ }^{11}$ As per literature review, the Activated carbon surface area is in excess of $500 \mathrm{~m} ., 12,13$ The density of activated carbon is $2100 \mathrm{~kg} / \mathrm{m}^{3}$.Compare to available reinforcement added with AA6061 activated carbon have some distinct advantages like readily available, cheap and good adsorption. ${ }^{14,15}$ 
In the present work, an attempt has been made to fabricate AA6061/activated carbon hybrid composite. ${ }^{16,17}$ The literature on previous work in the area of AA6061 metal matrix composite there is limited work is carried out by using activated carbon as reinforcement with AA6061. ${ }^{18,19}$ So this paper mainly focuses fabrication of hybrid composite and microstructure test like SEM (Scanning Electron Microscope), EDAX (Energy Dispersive Spectroscopy) and XRD ( X-Ray Diffraction) and thermal tests like FTIR(Fourier Transform Infrared spectroscopy) and Thermogravimetric (TGA) tests were carried out.

\section{EXPERIMENTAL}

The materials used to fabricate metal matrix composite are Al6061 rod and powdered activated carbon. The matrix for the composite is chosen as AA6061cylindrical rods (containing 0.4 percent Magnesium and 0.75 percent Silicon). Activated carbon in powdered form is used as reinforcement. The composition of AA 6061 is shown in the Table-1. AA6061 rods of 1500g was placed in a graphite crucible and which is coated to avoid contamination and heated using a furnace. The AA6061 rods were melted at a temperature of $900^{\circ} \mathrm{C}$ using a furnace shown in Fig.-1. Using mechanical stirrer the molten alloy is stirred to get a fine vortex. The Preheated activated carbon powder at a temperature of $600^{\circ} \mathrm{C}$ for 60 minutes was then added at a steady feed rate into the molten aluminum. 1 weight $\%$ of magnesium particles were used as wetting agent. Casting carried out with different parameters is shown in Table-2. The composite is prepared by adding different weight percentage of activated carbon like $2 \% 4 \% 6 \%$ and $8 \%$. From this experiment, it is evident there will be no proper mixing of reinforcement beyond $6 \%$ of activated carbon.

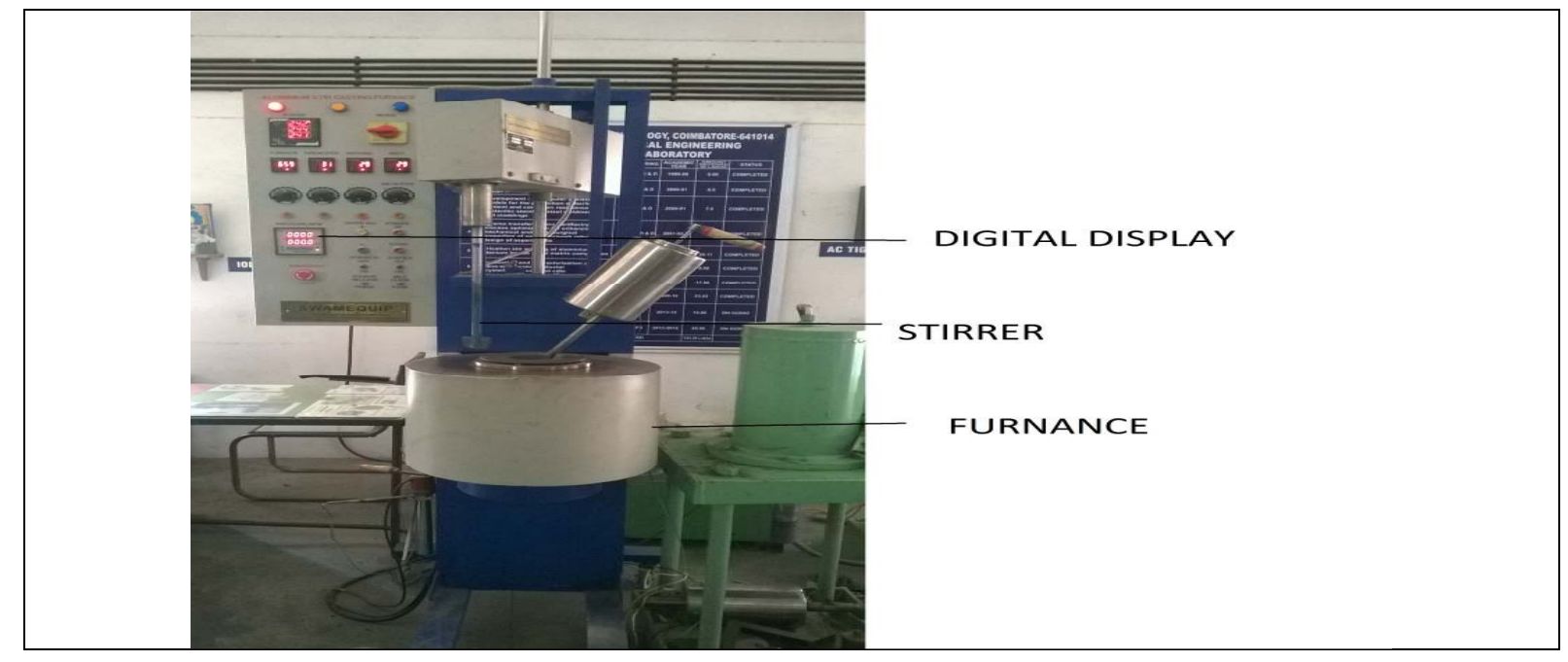

Fig.-1: Modified Stir Casting Apparatus

Table-1: Composition of the Al6061

\begin{tabular}{c|c|c}
\hline S. No. & Component & Weight \\
\hline 1. & Magnesium & 0.8 to 1.2 \\
\hline 2. & Silicon & 0.4 to 0.8 \\
\hline 3. & Iron & up to 0.7 \\
\hline 4. & Copper & 0.15 to 0.40 \\
\hline 5. & Zinc & up to 0.25 \\
\hline 6. & Titanium & up to 0.15 \\
\hline 7. & Manganese & up to 0.15 \\
\hline 8. & Chromium & 0.04 to 0.35 \\
\hline 9. & Others & 0.05 \\
\hline 10. & Aluminium & Remaining \\
\hline & &
\end{tabular}


RASĀYAN J. Chem.

Vol. 10 | No. 3 |784 - 789 | July - September | 2017

Table-2: Process Parameters

\begin{tabular}{c|c|c|c}
\hline S. No. & Parameters & Unit & Value \\
\hline 1. & Stirring Speed & RPM & 450 \\
\hline 2. & Furnace Temperature & ${ }^{0} \mathrm{C}$ & 650 \\
\hline 3. & Stirring time & Min & $2-3$ \\
\hline
\end{tabular}

\section{RESULTS AND DISCUSSION}

A series of microstructural tests and thermal tests were carried out on the developed composites with ASTM standards.

\section{SEM Analysis}

The microstructure of dissimilar weight $\%$ of activated carbon and AA 6061is shown in The Fig.-2a to 2c. The Figures-2a to c evidently shows Al alloy matrix with a homogeneous distribution of the activated carbon and there is no indication of cracks and porosity in castings. This is can be related to optimized process parameters employed for manufacturing of castings.
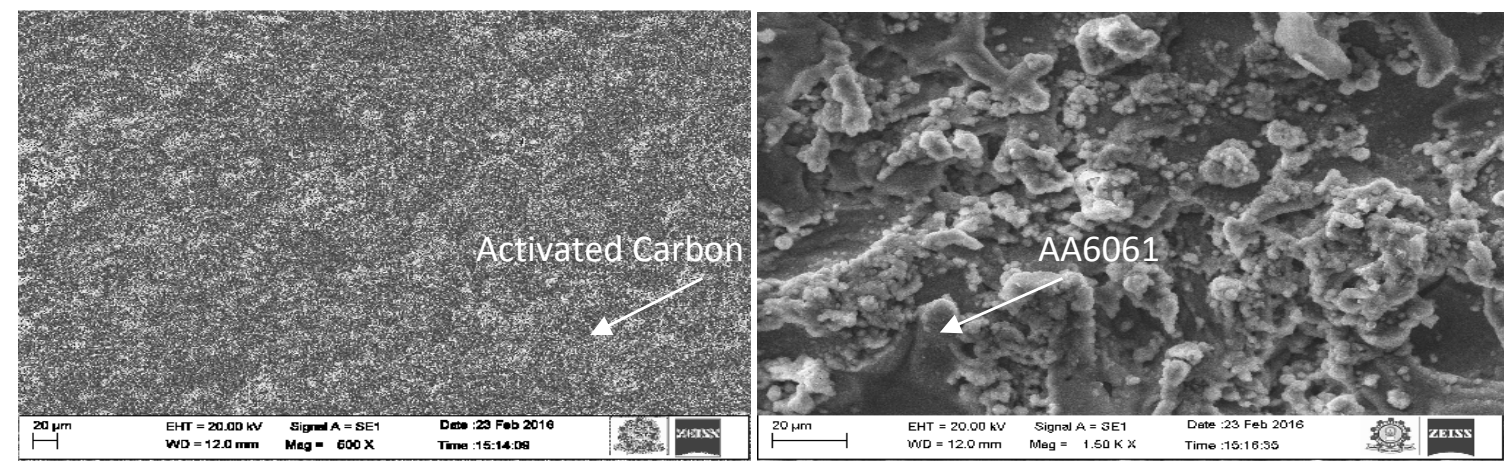

Fig.-2a: SEM image of AA6061 -2\%PAC, 2b: EM image of AA6061 - 4\%PAC

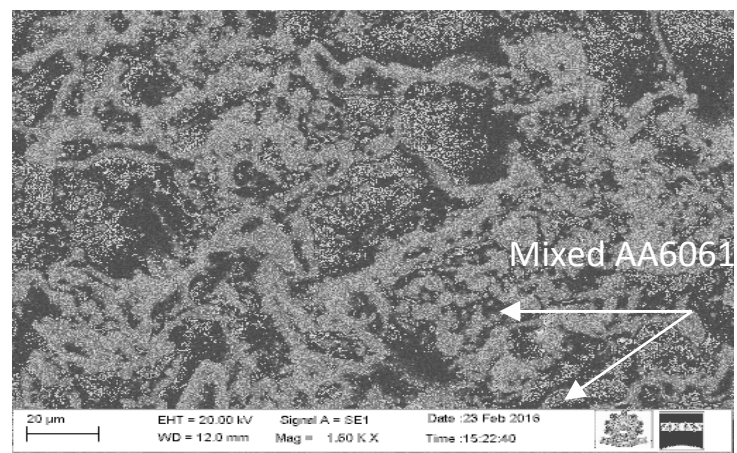

Fig.-2c: SEM image of Al6061 - 6\% PAC

\section{EDAX (Energy Dispersive Spectroscopy) Analysis}

From Figures-3a to 3c, EDS spectrum shows both the presence of $\mathrm{Al}$ alloy and activated carbon in the fabricated composite. The micrograph also shows that there is no agglomeration of the aluminum and activated carbon particles in the mixture. It is verified from Figures-3a to $3 \mathrm{c}$, that mechanical mixing and transfer of materials was taken place in between sliding surfaces, which leads to mechanically mixed layer formation on worn surfaces.

\section{XRD Analysis}

X- Ray Diffraction (XRD) of fabricated AA6061 and activated carbon-metal matrix composite is shown in Fig.-4. From the graph, it is verified that peaks corresponding to activated carbon and aluminium present in all materials, but the activated carbon peaks present in AA6061 composites and no reaction 
RASĀYAN $J$. Chem.

Vol. 10 | No. 3 |784 - 789 | July - September | 2017

product peaks are seen which confirms there is no chemical reaction between two activated carbon and aluminium.

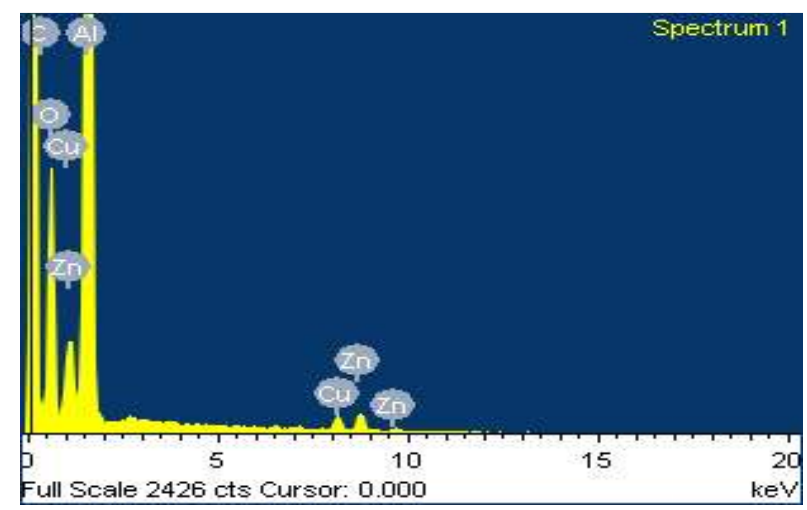

Fig.-3a: EDAX AA6061 - 2\%PAC

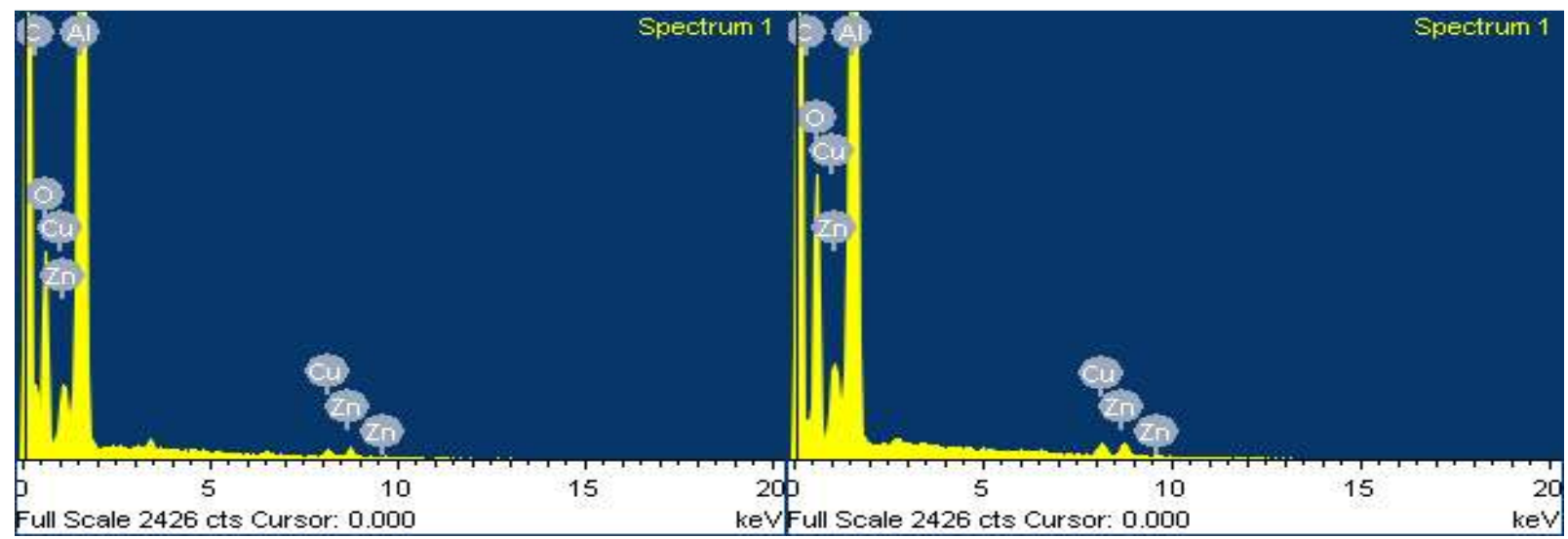

Fig.-3b: EDAX AA6061 - 4\%PAC; 3c: EDAX AA6061 - 6\%PAC

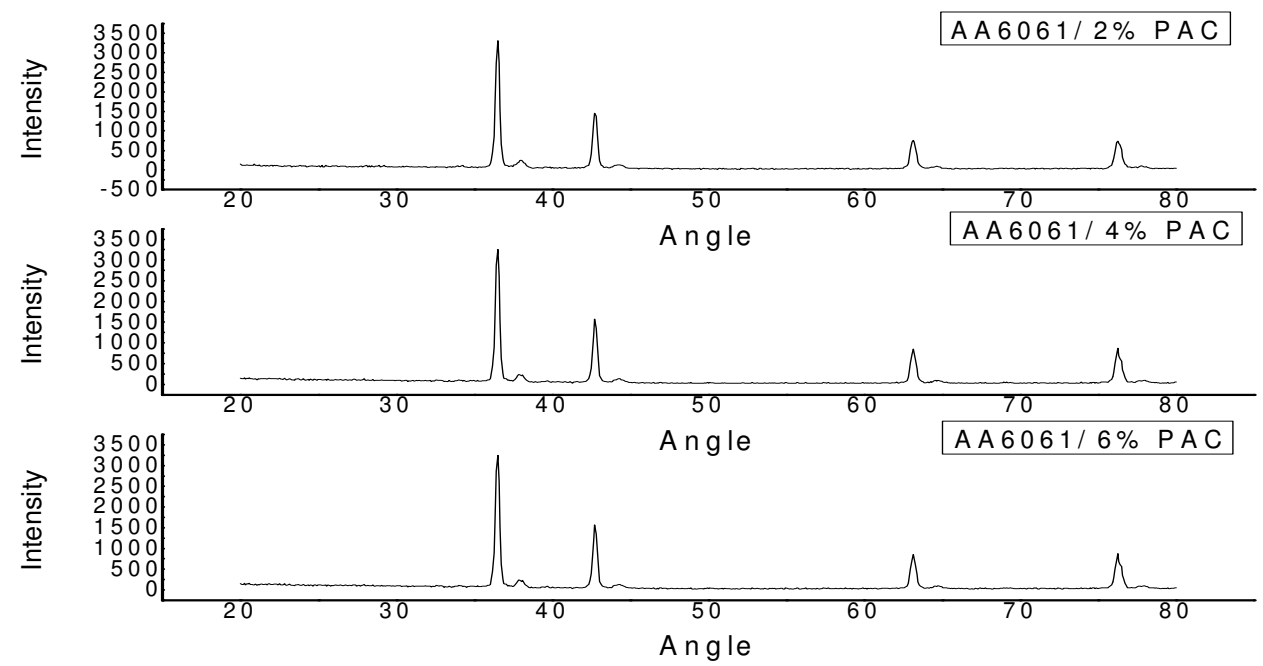

Fig.-4: X-Ray Diffraction results of casted AA6061/PAC Composite

With reference to XRD peaks of composites, it is evident that intensity of peaks resultant to activated carbon is higher with more amount of activated carbon in materials. This is for $\mathrm{Al} 6061$ with $6 \%$ of activated carbon which has high gross intensity. In all the three compositions XRD results show there are 
no formation other compounds. This shows that it has a good mixture. The results show that presence of aluminum in the largest peak and the activated carbon in the second largest peak. In this, a clearly visible activated carbon peak can be observed in the AA6061 composite. The increase in the intensity of the activated carbon peaks with the aluminum content of the composite is evident.

\section{Thermal Analysis}

\section{Fourier Transform infrared spectroscopy}

Fourier Transform Infrared spectroscopy is an IR radiation is passed through the sample. By passing IR radiation will give a quick and qualitative indication about the change in the chemical structure. The spectra of AA6061/Activated carbon metal matrix composite are shown in Fig.-5. The broad adsorption band in the region around $3100 \mathrm{~cm}^{-1}$ would be alkane residues are detected from $\mathrm{C}-\mathrm{H}$ stretching and $\mathrm{C}-\mathrm{H}$ deformation absorptions. C-H stretching absorption bands appear just below $3000 \mathrm{~cm}^{-1}$ one for symmetrical and other for asymmetrical vibrations.

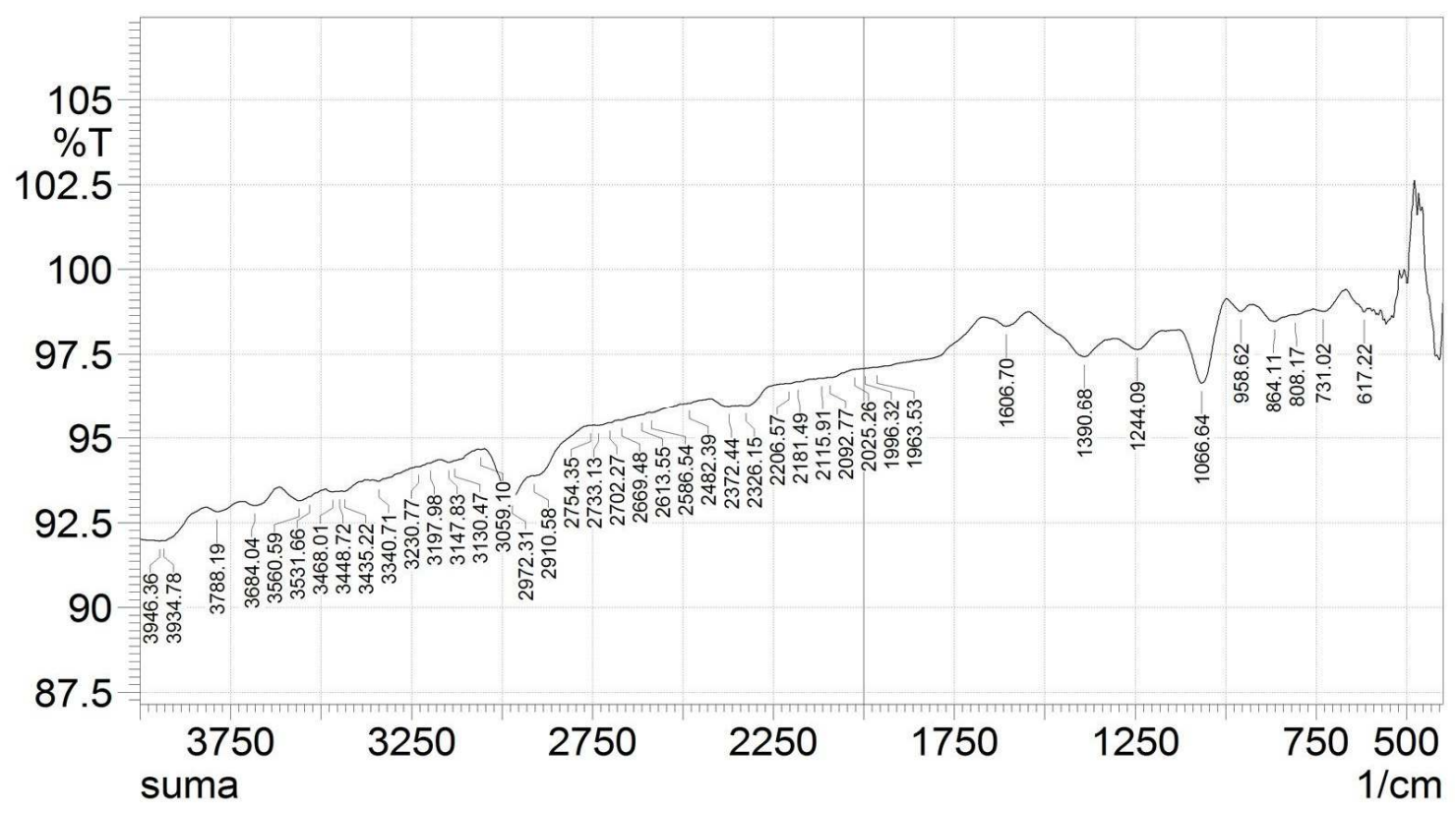

Fig.-5: FTIR of AA6061/Activated Carbon Composite

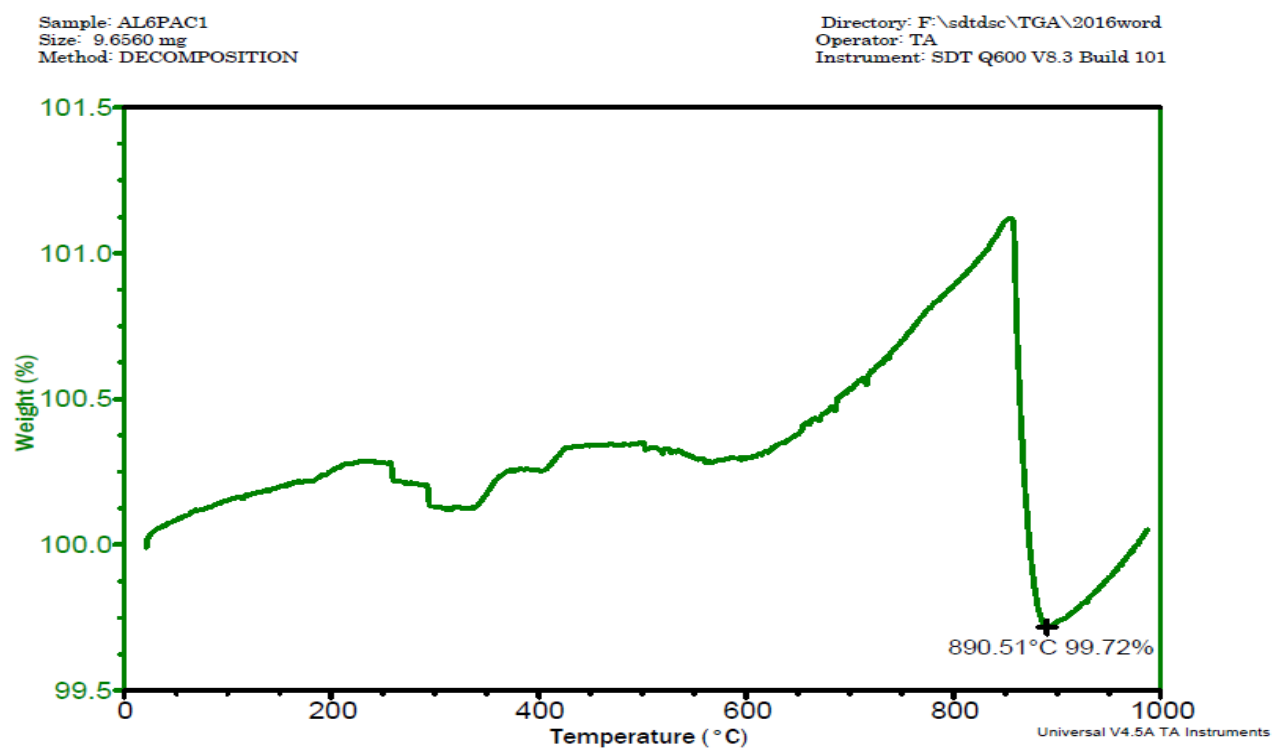

Fig.-6: TGA of AA6061/Activated Carbon Composite. 
RASĀYAN $J$. Chem.

Vol. 10 | No. 3 |784 - 789 | July - September | 2017

\section{Thermo Gravimetric Analysis}

The thermogravimetric analysis for the investigated AA-6061/ activated carbon are shown in Fig.-6. The thermogravimetric analysis results show the endothermic peaks originated in the range of $890-900^{\circ} \mathrm{C}$ due to the melting of Al-6061.It clearly shows that melting point of AA 6061 is improved rapidly by adding activated carbon as reinforcement.

\section{CONCLUSION}

The Al 6061/ activated composites were fabricated by modified stir casting technique with different weight percentage of reinforcement from $2 \%$ to $6 \%$ and the microstructure, mechanical properties were evaluated. From this study, the following conclusions are derived. The SEM micrographs show the presence of al6061 and activated carbon particles in the composite with homogeneous dispersion. FTIR graph shows there will be a quick and qualitative indication about the change in the chemical structure. From EDAX test EDS spectrum shows the presence of aluminium and carbon particles in the composite. XRD results indicate the presence of aluminum in the largest peak and the activated carbon in the second largest peak. In this, a clearly visible activated carbon peak can be observed in the AA6061 composite.In thermogravimetric analysis, the melting point of the composite is improved rapidly by adding activated carbon as reinforcement.

\section{REFERENCES}

1. Selvam, J. David Raja, D. S Robinson Smart, and I. Dinaharan, Energy Procedia, 34, 637(2013).

2. Hajizamani Mohsen, and Hamidreza Baharvandi, Adv. in Materials Physics and Chem., 1(2), 26(2011).

3. Bhandare, Rajeshkumar Gangaram and Parshuram M. Sonawane, Int. J. Eng. Adv. Technol., 3, 2249(2013).

4. Song, Yanpei, Shuangxu Bi, and Xiuqing Li. Engineering, 2(5), 360(2010).

5. Ramesh, Dasappa, Ragera Parameshwarappa Swamy, and T. K. Chandrashekar, J. of Minerals and Materials Characterization and Engg., 11(4), 353(2012).

6. Choi, Eun Young, Myung Chang Kang, Dong Hee Kwon, Dong Woo Shin, and Kwang Ho Kim, Journal of Materials Processing Technology, 187, 566(2007).

7. K. Q. Qiu, and Y. L. Ren, Journal of Minerals and Materials Characterization and Engg., 3(2), 91(2004).

8. M. Kathiresan, T. Sornakumar, Journal of Minerals and Materials Characterization and Engg., 9(1), 79(2010).

9. A. Ramesh, J. N. Prakash, A. S. Shiva Shankare Gowda, and Sonnappa Appaiah, Journal Journal of Minerals and Materials Characterization and Engg., 8(2), 93(2009).

10. K. K. Alaneme, and M. O. Bodunrin, Journal of Minerals and Materials Characterization and Engg., 10(12), 1153(2011).

11. Dasappa Ramesh, Ragera Parameshwarappa Swamy, and T. K. Chandrashekar, Journal of Minerals and Materials Characterization and Engg., 11(4), 353(2012).

12. G. Ramanan, J. Edwin Raja Dhas, M. Ramachandran and G. Diju Samuel, Rasayan J. Chem., 10(2), 375(2017)

13. H. R. Ezatpour, Seyed Abdolkarim Sajjadi, M. H. Sabzevar, and Y. Z. Huang, Materials Science and Engineering: A, 607, 589(2014).

14. G. L. Rajesh, V. Auradi, and S. A. Kori,Transactions of the Indian Ceramic Society,75(2),112(2016).

15. Hajihashemi Mahdi, Behzad Niroumand, and Morteza Shamanian, Metallurgical and Materials Transactions B, 46(2),780-792(2015).

16. Haque Serajul, Akhtar Hussain Ansari, and Prem Kumar Bharti, Arabian Journal for Science and Engineering, 41(11), 4303(2016).

17. Mahdavi Soheil, and Farshad Akhlaghi, Journal of Materials Science, 46(5),1502(2011).

18. B. Ravi, B. Balu Naik, and J. Udaya Prakash, Materials Today: Proceedings, 2(4), 2984(2015).

19. A. Ramesh, J. N. Prakash, A. S Shiva Shankare Gowda, and Sonnappa Appaiah, Journal of Minerals and Materials Characterization and Engg., 8(2), 93(2009).

[RJC-1748/2017] 